\title{
EL PSICOANÁLISIS EXISTENCIAL
}

\author{
EXISTENTIAL PSYCHOANALYSIS \\ JuAN CARLOS GÓMEZ GARCÍA \\ Universidad de Barcelona \\ Joancarles61.gomez@gmail.com
}

\begin{abstract}
RECIBIDO: 15 DE JUNIO DE 2012
ACEPTADO: 4 DE SEPTIEMBRE DE 2012
\end{abstract}

\begin{abstract}
Resumen: El psicoanálisis existencial es una de esas críticas constructivas derivadas del psicoanálisis empírico que intenta abrirse camino como alternativa, renovación y modelo de terapia psicoanalítica. Ha encontrado una fundamentación óntico-ontológica desde la cual mostrar al ser descrito tal como se manifiesta en tres estadios concretos: el para-sí, en-sí y para-otro, para llegar a ver que las relaciones con los otros son las que nos provocan esos desequilibrios psíquicos. Nuestro psicoanálisis se plantea como una superación al psicoanálisis empírico en el rechazo al postulado del inconsciente y en la elección que renuncia a suponer una acción mecánica del medio sobre el sujeto considerado a abandonar la simbología utilizada hasta entonces. El psicoanálisis existencial deberá ser enteramente flexible y amoldable a los menores cambios observables en el sujeto, ya que se trata de descubrir una elección no un estado. Como el psicoanálisis existencial tiene como objeto descubrir una elección, deberá tener siempre presente que su objeto no es algo hundido en las tinieblas del inconsciente, sino una determinación consciente y libre. Finalmente, la propuesta es una terapia psicoanalítica ya que la persona es una constante proyección en el mundo, el método existencial, se orienta desde el principio hacia una comprensión del ser y no debe asignarse otro objetivo que encontrar el ser y la manera de ser del ser frente a ese ser.
\end{abstract}

Palabras clave: Psicoanálisis existencial, psicoanálisis empírico, Yo, para-sí, en-sí, para-otro, consciencia

\begin{abstract}
Existential Psychoanalysis is one of the most constructive critics based on empirical psychoanalysis which attempts to open up new paths as an alternative, renovation and model of psychoanalytical therapy. An ontic-ontological foundation has been discovered from which it can be described in 3 different concrete states: for someone, in someone or for someone else, to be able to see that our relationships with others are those which cause psychic unbalance. Our psychoanalysis overcomes empirical psychoanalysis in rejection to postulate from the unconscious and in the election which renounces to suppose a mechanical action from the medium on the subject considered to abandon the symbology used until then. Existential psychoanalysis should be completely flexible and changeable to the minor changes which can be observed in the subject, now that it is a case of discovering an election not a state. Due to the fact that the psychoanalysis has as objective to discover an election, it should always have present that its objective is not something united in the darkness of the unconscious, but more of a conscious and free determination. Lastly, the proposition is a psychoanalytical therapy now that the person is a constant projection in the world, the existential method, which is oriented from the beginning towards an understanding of the being and another
\end{abstract}


objective should not be assigned other than find ways of being and the way of being against that being.

Keywords: existential psychoanalysis, empirical psychoanalysis, I, for itself, in-itself, for-other consciousness

\section{Del psicoanálisis empírico al psicoanálisis existencial}

El psicoanálisis tuvo, ha tenido $\mathrm{y}$, seguramente, tendrá un gran alcance $\mathrm{y}$ repercusión en todos los ámbitos culturales e intelectuales por los que transite, es una metodología mágica tanto por su contenido como por su posición; sin embargo, parece ser que estas últimas décadas está siendo objeto de críticas más destructivas que constructivas en referencia a su fundamentación y fundamentador, la cual cosa no le exime de ser una de las metodologías más atractivas desde su inicio histórico. Tales críticas $^{1}$ más que desvirtuarlo, han servido para incrementar todavía más el interés por los entresijos del Yo. El psicoanálisis existencial es una de esas críticas constructivas derivadas del psicoanálisis empírico que intenta abrirse camino como alternativa, renovación y modelo de terapia psicoanalítica. Desde el origen del psicoanálisis empírico hasta la propuesta sartreana de un psicoanálisis existencial, han sido muchas las modificaciones $^{2}$ que se han realizado en la psicología de Freud desde sus cimientos más internos; el psicoanálisis existencial que aquí proponemos no es exactamente una modificación, más bien se trata de una restructuración, de una nueva visión psicoanalítica basada en una fundamentación ontológica que matiza los elementos estructurales de la mente definidos por Freud. El resultado es una metodología más directa, más descriptiva del ser existencial y no del ser ególico; y menos especulativa e interpretativa tal como mostraremos a continuación.

El puente de unión que hemos elegido ente Freud y Sartre es Binswanger ${ }^{3}$ quien mantuvo, pese a sus diferencias con Freud, una intensa correspondencia

\footnotetext{
1 Webster, Richard, Por qué Freud estaba equivocado, Ediciones Destino, Barcelona, 2002 y Onfray, Michel, Freud. El crepúsculo de un ídolo, Editorial Taurus, Madrid 2011, son los dos referentes más inmediatos del momento.

2 La gran cantidad de bibliografía al respecto nos desbordaría, me remito a los autores más inmediatos como: Donald, W. Winnicott, Wilhelm Reich, Georg Groddeck, Melanie Klein, Carl G. Jung, Jacques Lacan, Françoise Dolto, Theodor Reik, Otto Fenichel, Sándor Ferenczi, Elene Deutesch, Karl Abraham, Anna Freud, Ernest Jones y Ludwig Binswasger. Todos ellos pueden consultarse en la biblioteca del psicoanálisis de la Editorial RBA, 2006.

3 Ludwig Binswanger, Kreuzlingen, 13 de abril de $1881-5$ de febrero de 1966. Fue un psiquiatra suizo pionero en el campo de la psicología existencial.
} 
epistolar ${ }^{4}$ hasta el 1939. Ludwig Binswanger, es considerado el primer médico en integrar a la psicoterapia el existencialismo, una teoría que expuso en su libro publicado en 1943 Grundformen und Erkenntnis menschlichen Daseins. Su obra tiene una doble intención: en primer lugar, dar primacía a algo que se nombra como esencia del hombre conforme al pensamiento fenomenológico de Husserl, donde la experiencia fenomenológica será la que lleve a la esencia de la persona enferma y la presente a nuestra percepción permitiendo que se exprese el contenido dado de modo puramente fenomenológico, es decir, sin interferencias teóricas establecidas previamente. En segundo lugar, pretende satisfacer el deseo de Freud en introducir al psicoanálisis en la práctica psiquiátrica. Surgen inmediatamente incompatibilidades con el sistema freudiano, no es el de la entrada en escena del inconsciente en el campo de la psicopatología, sino el de la fragmentación teórica de la psiquiatría y su incapacidad para comprender desde ahí la esencia del hombre. Binswanger da prioridad al objeto teórico psiquiatría ante el objeto teórico psicoanálisis y, en consecuencia, no considera al psicoanálisis como el tema central de su psicología, es meramente una temática recurrente. Afirma que el psicoanálisis no divide la personalidad en funciones o géneros de cualquier modo tipificados del acontecer psíquico, sino que penetra manteniendo íntegra su unidad, en sus elementos esenciales internos. Como primera característica, el psicoanálisis destaca lo que Binswanger denomina la contradicción interna de la personalidad. Freud considera al hombre no como un autómata que recibe de la realidad solamente estímulos, sino como un ser espiritual que juzga conforme a normas y valores; así el problema fundamental del psicoanálisis es cómo valora el hombre al mundo y así mismo como una parte del mundo. Otra característica del psicoanálisis de Freud es considerar cada uno de los análisis como si fuera el primer y único análisis realizado, que ningún análisis tiene nada en común con otro, y que para realizar un análisis el analista debe procurar olvidar toda teoría y poner entre paréntesis todo saber, para limitarse únicamente a la escucha del discurso del paciente. La consecuencia es que cada análisis puede decirse que constituye por sí mismo una modalidad del análisis y es en este sentido en el que Binswanger se refiere a las modalidades de experiencia posibles como no pluralizables, ya que eso supondría dar cabida bajo un mismo concepto a experiencias que de antemano se ven bien diferentes. Otra de las diferencias notables entre el psicoanálisis freudiano y el existencial de Binswanger, es que este último jamás abandonará su posición filosófica y, en esa línea, expulsará al inconsciente del campo de consideración analítico. La cuestión que se plantea ahora es ¿qué queda del psicoanálisis freudiano en el existencial de Binswanger? Además, vemos como a

${ }^{4}$ Cfr. Binswanger, Ludwig, Obras Escogidas, RBA, Biblioteca del psicoanálisis, Barcelona, 2006. 
partir del 1922, su afiliación a la fenomenología se consolida totalmente posicionándose así en argumentos distantes de los de su maestro.

Parece ser que la fenomenología también hizo mella en Jean Paul Sartre, quien encontró en esta filosofía, según sus palabras, aquello que andaba buscando: ir a las cosas mismas, a la existencia del ser, para desde ahí analizar todo lo que de él se derive que es en el fondo su existir. Sartre fue más allá que Binswanger, fundamentó ontológicamente al Yo, lo describió y nos mostró sus relaciones con la exterioridad haciendo surgir de ese modo la necesidad de un mecanismo analítico, el psicoanálisis existencia.

\section{Fundamentación ontológica del psicoanálisis existencial}

Partimos del principio óntico-ontológico que exige definir de forma descriptiva el Yo. La misma definición del Yo significa un alejamiento notablemente de nuestro propio Yo, la cual cosa en sí ya es una contradicción. Por ello hablamos de una descripción del Yo y, en definitiva, de una definición descriptiva para que el Yo no se pierda en fundamentos subjetivistas ni objetivistas. El Yo no puede ser aprehendido, ni entendido en el sentido epistemológico como han querido algunos, el Yo es vivido porque Yo soy yo mismo y, en consecuencia, no puedo distanciarme de él. Cuando pretendo conocer algo establezco una distancia entre Yo y aquello que quiero conocer (relación sujeto-objeto), eso jamás se podrá realizar con el Yo, porque de él me sé de forma intuitiva, evidente y necesaria. Si me posicionará desde otra perspectiva para analizar mi Yo, esa otra perspectiva sería yo mismo. Es claro entonces que el Yo no es un conocimiento sino una intuición donde se dan los mecanismos abstractivos, judicativos y racionales. Empero la expresividad del Yo, la manifestación externa, su exterioridad manifiesta es siempre empírica y es lo que se manifiesta siendo, no un deber de ser. Es el Yo-empírico que al dimensionarse en el mundo, al encontrarse como ser arrojado, intenta salvaguardar su egocidad, defender su Yo interno, su principio de identidad que ahora se verá afectado en esta exterioridad manifiesta que será descubierta en su relación con el Otro. He aquí la trilogía descrita en $E l$ ser y la nada, un para-sí, un en-sí y un para-otro que constituyen la descripción ontológica del ser y que cada uno de ellos, siendo un todo, un bloque compacto porque el ser es absoluto- significan un conflicto de unidad y de exterioridad. El ser, al exteriorizarse, se encuentra en peligro, en acoso constante, es una situación dialéctica que mantiene para entender la contradicción a la que está sujeto: defender su interioridad sin caer en el solipsismo. Con otras palabras, el reconocimiento (evidencia intuitiva de ser) de mi individualidad por mí mismo, la certeza de mi ser, ahora se ve entredicha y amenazada por la relación que 
mantengo en lo exterior. Así necesito mecanismos de defensa para mantener mi identidad inalterada, cosa que jamás logro. Es claro que el individuo busca proyectarse para fundamentar su ser y, demás, como la realidad humana se anuncia y define por los fines que persigue, el estudio y clasificación de dichos fines se hace inevitable. No puede eludir la relación externa porque recordemos que el Para-sí es una perspectiva de su libre proyecto, del impulso por el cual se arroja a su fin, el cual forma parte de la subjetividad absoluta como límite trascendente y objetivo de ésta. Es del todo necesario interrogar a este fin mismo para descubrir en él los mecanismos que pueden interferir en su desarrollo existencial; es decir, debemos hondear en lo más profundo de nuestro ser para ver qué estructura, o estructuras, le aturden. Y según Sartre, "Esto es lo que ha pretendido la psicología empirista afirmando que un hombre particular se define

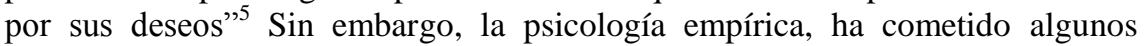
errores importantes que la han alejado de la auténtica comprensión sobre la fundamentación del ser y, en consecuencia, se ha desviado notablemente de el problema original del sujeto, veámoslo.

El psicólogo empírico, al definir al hombre por sus deseos, sigue siendo víctima de la ilusión sustancialista porque el deseo es una aspiración -de sermenos real que imaginaria. Ve el deseo como si existiera en el hombre a título de contenido de su conciencia, y cree que el sentido del deseo es inherente al deseo mismo. Así, evita todo cuanto pudiera evocar la idea de una trascendencia. Por ejemplo, si deseo un coche, éste no puede residir en mi deseo y no es distinto de la conciencia; así que es claro que no hay que considerar los deseos como pequeñas entidades psíquicas que habitan la conciencia, más bien los deseos son la conciencia misma en su estructura original pro-yectiva y trascendente, en tanto que es por principio conciencia de algo ${ }^{6}$. Y, precisamente, el deseo interpretado como entidades manifiestas y habitantes de nuestra conciencia, es uno de los pilares donde se fundamenta el psicoanálisis empírico. Además, el psicólogo empírico considera que está determinada, completada y fundamentada la investigación psicológica una vez que se ha logrado hacer el inventario del conjunto concreto de los deseos empíricos; es decir, un hombre se definirá por el sumatorio de tendencias que haya podido establecer la observación empírica. Naturalmente, el psicólogo no siempre se limitará a efectuar la suma de esas tendencias: se complacerá en sacar a la luz sus parentescos, concordancias y armonías, tratará de presentar el conjunto de los deseos como una organización sintética, en la cual cada deseo actúa sobre los otros e influye sobre ellos, creando un sistema peligroso de analogía. Tal análisis psicológico parte del

\footnotetext{
${ }^{5}$ SARTRE, Jean Paul, El ser y la nada, Alianza Editorial, Madrid 1989, pág. 580

${ }^{6}$ Ibídem, pág. 580.
} 
postulado de que un hecho individual es producido por la intersección de leyes abstractas y universales, donde lo abstracto se muestra anterior a lo concreto. "Por ejemplo, al intentar explicar la personalidad de Flaubert dicen construirla a través de la siguiente observación: su efervescencia de su sangre joven se convirtió en una pasión por la literatura. Podemos ver como este postulado no logra explicar lo que constituye la individualidad del pro-yecto considerado: que la "necesidad de sentir en exceso" -esquema universal- sea engañada y canalizada convirtiéndose en necesidad de escribir, no es la explicación de la "vocación de Flaubert: al contrario, es lo que hay que explicar"7. El error es relegar lo individual puro, expulsado de la subjetividad de Flaubert, a las circunstancias exteriores de su vida, tal como apunta Sartre. Vemos como los psicólogos y psiquiatras quedan satisfechos cuando capta el nexo, por ejemplo, entre castidad y misticismo o entre debilidad e hipocresía. Pero, lo más importante es que continuamos ignorando la relación concreta entre esa castidad y el contenido individual del misticismo. También vemos como la psiquiatría queda satisfecha una vez que ha sacado a la luz las estructuras generales de los delirios y no trata de comprender el contenido individual y concreto de la psicosis, que por otro lado significaría llegar a la autenticidad del problema que desequilibra al individuo. Se exige algo irreductible cuya irreductibilidad sea evidente para nosotros y que no se ofrezca como el postulado del psicólogo y el resultado de su negativa o de su incapacidad de ir más lejos, sino que, al ser verificado produzca en nosotros un sentimiento de satisfacción, de concordancia entre mi Yo y el Otro. Esta exigencia no es la indagación pueril de un "porque" que no daría lugar a ningún otro "¿por qué?”, muy al contrario es una experiencia fundada sobre una comprensión óntico-ontológica de la realidad humana y sobre consiguiente negativa a considerar al hombre como analizable y como reductible a datos primeros, a deseos (o "tendencias") determinados, soportados por el sujeto como las propiedades por un objeto. Si realizamos la reducción tal como la psicología empírica propone, el hombre se reducirá al simple sumatorio de tendencias irreductibles. La consecuencia nociva del psicoanálisis empírico es que, en su estructura, el hombre desaparece: no encuentra ya aquel al cual le ha ocurrido tal o cual aventura, está difuminado; o bien, al buscar a la persona nos encontramos con una sustancia metafísica, inútil y contradictoria, o también, el ser que buscamos se esfuma en una polvareda de fenómenos vinculados entre sí por meras relaciones externas.

Se trata de acercarnos a la comprensión del Otro desde nosotros mismos, sin ningún tipo de juego psicológico que implique una posición accidental o recreativa de los Yos. Lo que cada uno de nosotros debe exigir en su propio

\footnotetext{
${ }^{7}$ Ibídem, pág. 581
} 
esfuerzo por comprender al prójimo es, ante todo, no tener que recurrir jamás a esa idea de sustancia, inhumana porque está más acá de lo humano, y, después, que a pesar de ello el ser considerado no se disuelva en polvo, sino que pueda descubrirse en él esa unidad de responsabilidad siempre personal que se encuentra manifiesta en la relación social. Así, debemos renunciar a los irreductibles de detalle, porque éstos confunden y desorienta, y, tomando como criterio la evidencia misma, no detenernos en el análisis hasta que sea evidente que no podemos ni debemos ir más lejos. En palabras de Sartre, "no debemos tratar de reconstruir a una persona por sus inclinaciones, así como no ha de intentarse reconstruir la sustancia o sus atributos por la suma de sus modos" ${ }^{\prime 8}$. Es decir, todo deseo presentado como irreductible es una contingencia absurda y arrastra a la absurdidad a la realidad humana como un todo. Veamos el ejemplo que nos da Sartre:

$\mathrm{Si}$, por ejemplo, declaro que a uno de mis amigos "le gusta remar", propongo deliberadamente detener la investigación ahí. Pero, por otra parte, constituyo así un hecho contingente e inexplicable, que, si bien tiene la gratuidad de la decisión libre, no tiene, en cambio, la correspondiente autonomía". No se puede considerar esa inclinación a remar como el proyecto fundamental de cualquier hombre, ya que considerarla como proyecto fundamental significa algo secundario y derivativo. Al considerar la tendencia hacia el remo como elemento vinculante, habrá quien dirá que el sujeto, en cuestión, es considerado un deportista y campesino, porque le gustan los esfuerzos violentos y al aire libre, sin embargo, de esa forma se colocará por debajo del deseo que se quiere explicar, tendencias más generales y menos diferenciadas que son al deseo. De este modo la explicación psicológica consiste en hacer resaltar metas relacionadas de concomitancia o de sucesión constante en una simple clasificación ${ }^{9}$.

Así, la cuestión se sintetiza en lo siguiente: Primero, si admitimos que la persona es una totalidad, entonces no la podemos recomponer por un sumatorio u organización de sus tendencias que descubrimos empíricamente en ella. Segundo, en cada inclinación y en cada tendencia, se expresa la persona toda entera de una manera especial, podemos decir que la persona se expresa en cada uno de sus atributos. Eso nos obliga a investigar en cada tendencia, en cada conducta del sujeto, una significación que la trasciende. Es decir, esa actitud empírica es de por sí la expresión de la elección de un carácter inteligible. Y, contrariamente a lo que interpretan los psicólogos empiristas, no hay misterio en

${ }^{8}$ SARTRE, Jean Paul, El ser y la nada, Alianza Editorial, Madrid 1989, pág. 584

${ }^{9}$ Ibídem, pág. 585 
que eso sea así, ni se da un plano inteligible -inconsciente- que sólo podríamos pensar. Ni el carácter singular de la elección inteligible no se efectúa primero en algún inconsciente o en el plano nouménico) para expresarse después en tal o cual actitud observable; es más, ni siquiera tiene preeminencia ontológica sobre la elección empírica, sino que es, por principio, aquello que debe siempre desprenderse de la elección empírica como su más allá y como la infinitud de su trascendencia. De tal manera que “(...) si remo por el río, no soy nada más -ni aquí ni en oro mundo- que ese proyecto concreto de remar" 10 .

Tercero, pero este proyecto mismo, en tanto que totalidad de mí ser, expresa mi elección original en condiciones particulares, es la elección de mí mismo como totalidad en esas circunstancias. De ahí la necesidad de un método especial para extraer esa significación fundamental que el proyecto lleva consigo y que es el secreto individual de su ser-en-el-mundo.

Cuarto, se intentará descubrir y extraer el proyecto fundamental común a las diversas tendencias empíricas de un sujeto comparándolas entre sí, y no recomponiéndolas o sumándolas simplemente. Es preciso compararlas entre sí ya que en cada una de ellas está la persona en su totalidad.

Quinto, para este propósito tenemos que reconocer ciertos caracteres comunes y tratar de clasificarlos en categorías más amplias, hay que diseñar encuestas individuales sobre los casos que podamos estudiar más fácilmente porque es evidente que hay una infinidad de proyectos posibles, como hay una infinidad de hombres posibles. Hemos de seguir una máxima, un principio psicoanalítico existencial que se guiará por los datos obtenidos en las encuestas: “(...) no detenernos sino ante la irreductibilidad evidente, o sea, no creer jamás que se ha alcanzado el proyecto inicial hasta que el fin proyectado aparezca como el ser mismo del sujeto que consideramos". Por eso no podremos limitarnos a clasificaciones en "proyecto auténtico" y "proyecto inauténtico de sí mismo" ${ }^{11}$. Eso precisamente es lo que quiere establecer Heidegger.

\footnotetext{
${ }^{10}$ Ibídem, pág. 585

${ }^{11}$ Sartre crítica a Heidegger diciendo que afirmar el ser inauténtico significa conducirse a una clasificación viciada por una preocupación ética: actitud del sujeto hacia su propia muerte: "Si la muerte es angustiosa y, por ello, podemos rehuir la angustia o arrojarnos resueltamente a ella, es un truismo decir que lo hacemos por apego a la vida. Entonces, la angustia ante la muerte, la decisión resuelta o la huída a la inautenticidad no pueden ser consideradas como proyectos fundamentales de nuestro ser: sólo será posible comprenderlas, por el contrario, sobre el fundamento de un proyecto primero de vivir, es decir, sobre una elección originaria de nuestro ser" (SARTRE, Jean Paul, El ser y la nada, Alianza Editorial, Madrid 1989, pág. 587).
} 
Pensamos que conviene ir más allá de los resultados de la hermenéutica heidegeriana hacia un proyecto aún más fundamental el cual debe cumplir las siguientes exigencias:

1. No debe remitir a ningún otro.

2. Debe ser concebido por sí.

3. No puede referirse ni a la muerte ni a la vida, ni a ningún carácter particular de la condición humana.

4. El proyecto original de un para-sí no puede apuntar sino a su propio ser. El proyecto de ser o deseo de ser o tendencia a ser no proviene de una diferenciación fisiológica o de una contingencia empírica; no se distingue del ser del para-sí. En realidad, el para-sí, es un ser cuyo ser está en cuestión en su ser en forma de proyecto de ser. Serpara-sí es hacerse anunciar lo que se es por un posible, bajo el signo de un valor. Lo posible y el valor pertenecen al ser del para-sí. Ya que el para-sí se describe ontológicamente como carencia de ser, y el posible pertenece al para-sí como aquello que le falta, así como el valor infesta al para-sí como la totalidad de ser fallida. El para-sí elige porque es carencia; la libertad se identifica con esa carencia, pues es el modo de ser concreto de la carencia de ser. Ontológicamente es lo mismo decir que el valor y el posible existen como límites internos de una carencia de ser que no podría existir sino en tanto que tal carencia, o decir que la libertad, al surgir, determina su posible y con ello circunscribe su valor.

Así, es imposible remontarse más allá del ser, y entre proyecto de ser, posible y valor, por una parte, y el ser por otra, no hay ninguna diferencia: "El hombre es fundamentalmente deseo de ser, y la existencia de este deseo no tiene que ser establecida por una inducción empírica: es el resultado de una descripción a priori del ser-para-sí", que bien podemos definir óntica-ontológica. Ya que el deseo es carencia y el para-sí es el ser que es para sí mismo su propia carencia de ser. Así, el proyecto de ser es el proyecto original que se expresa en cada una de nuestras tendencias empíricamente observables, o: "cada tendencia empírica está en el proyecto original de ser en una relación de expresión y de satisfacción simbólicas, tal como, en Freud, lo están las tendencias conscientes con relación a los complejos y a la libido original"12. Cabe precisar que no hay primero un deseo de ser y después numerosos sentimientos particulares, sino que el deseo de ser sólo existe y se manifiesta en y por los celos, la avaricia, el amor al arte, la

12 SARTRE, Jean Paul, El ser y la nada, Alianza Editorial, Madrid 1989, p. 588 
cobardía, el coraje, en definitiva, las mil expresiones contingentes y empíricas que hacen que la realidad humana no nos aparezca nunca sino al ser puesta de manifiesto por este hombre, por una persona singular.

Ahora, nos toca forzosamente definir la realidad humana dentro del contexto que estamos exponiendo: la realidad humana debe entenderse, por todo lo expuesto, como el deseo de ser- en-sí, es decir, su exterioridad. Sabemos que el para-sí es el ser que es para sí mismo su propia carencia de ser, y el ser que al para-sí le falta es el en-sí. El para-sí surge como nihilización del en-sí, y esta nihilización se define como proyecto hacia el en-sí: entre el en-sí nihilizado y el en-sí proyectado, el para-sí es nada. Por eso el objetivo y el fin de la nihilización que soy, es el en-sí. Mas, el en-sí que la realidad humana desea, no puede ser puro en-sí contingente y absurdo comparable al que ella encuentra y nihiliza. La nihilización es asimilable a una rebelión del en-sí que se nihiliza contra su contingencia. Decir que el para-sí existe su facticidad, es lo mismo que decir que la nihilización es el vano esfuerzo de un ser por fundar su propio ser, y que es el retroceso o distanciamiento fundador que produce el ínfimo desnivel por el cual la nada entra en el ser. Y, en este punto, volvemos a lo de antes, el ser que es objeto del deseo del para-sí es un en-sí que fuera su propio fundamento, es decir, que fuera a su facticidad lo que el para-sí es a sus motivaciones. Además, el para-sí, al ser negación del en-sí, no podría desear el puro y simple retorno al ensí. Aquello que por lo cual el para-sí reclama al en-sí es la totalidad destotalizada: en-sí nihilizado en para-sí, o sea, el para-sí proyecta ser en tanto que para-sí un ser que sea lo que es; el para-sí. Ello es posible porque en tanto que ser que es lo que no es y que no es lo que es, proyecta ser lo que es; en tanto que conciencia quiere tener la impermeabilidad y la densidad infinita del en-sí, y al no conseguirlo se dice que es nada de ser; pero en tanto que nihilización del en-sí y perpetúa evasión de la contingencia y de la facticidad, quiere su propio fundamento. Por ello el posible es pro-yectado como aquello que le falta al parasí para convertirse en en-sí-para-sí, que es lo que podemos denominar la unicidad del ser o el ser absoluto, y el valor fundamental que preside a este proyecto es el en-sí-para-sí, es decir, el ideal de una conciencia que fuera fundamento de su propio ser-en-sí por la pura conciencia que tomaría de sí misma. A este ideal se le puede llamar Dios, por ejemplo, porque pude decirse que lo que hace concebible mejor que nada el proyecto fundamental de la realidad humana es que el hombre es el ser que proyecta ser Dios: "El hombre es fundamentalmente deseo de ser Dios"13.

13 Ibid, pág. 589-590 
El deseo de ser se realiza siempre como el deseo de una manera de ser y este deseo de una manera de ser se expresa a su vez como el sentido de las miríadas de deseos concretos que constituyen la trama de nuestra vida consciente. De esta manera surgen arquitecturas simbólicas muy complejas. En el deseo empírico podemos ver claramente una simbolización de un deseo fundamental y concreto que es la persona y que representa la manera en que ésta ha decidido que el ser esté en cuestión en su ser. El deseo empírico es el deseo de ser en general y por ello se considera como la realidad humana en la persona, que es lo que constituye su comunidad con el prójimo, lo que permite afirmar que hay una verdad del hombre y no sólo individualidades incomparables. La existencia como totalidad pertenece al deseo libre y fundamental, es decir, a la persona. El deseo empírico es una simbolización de ese deseo, al cual remite y del cual toma su sentido. Por otra parte, el deseo de ser, en su pureza abstracta, es la verdad del deseo concreto fundamental, pero no existe a título de realidad. Así, el proyecto fundamental, o persona, o libre realización de la verdad humana está doquiera en todos los deseos. Y la estructura abstracta y ontológica "deseo de ser", representa la estructura fundamental y humana de la persona, pero no puede constituir una traba para su libertad, ya que la libertad es asimilable a la nihilización: el único ser que puede ser llamado libre es el ser que nihiliza su ser, sin embargo sabemos que la nihilización es carencia de ser. La libertad es precisamente el ser que se hace carencia de ser, pero como el deseo es idéntico a la carencia de ser, la libertad sólo puede surgir como ser que se hace deseo, como proyecto-para-sí de ser en-sí. Recordemos que la libertad es surgimiento inmediatamente concreto y no se distingue de su elección, es decir, de la persona. Ayudándonos de Sartre, creemos haber establecido la verdad humana por medio de una fenomenología ontológica, donde la simbología de los deseos empíricos debe ser objeto de investigaciones propiamente psicológicas: la observación, la inducción y la experimentación, tienen que orientar al filósofo sobre las relaciones comprensibles que pueden unir entre sí diferentes deseos o diferentes comportamientos, así como sacar a la luz ciertas conexiones concretas entre "situaciones experimentalmente definidas y el sujeto de la experiencia". Sartre nos hace notar que para la clasificación y determinación de los deseos fundamentales o personas, ninguno de los métodos puede convenir: no puede tratarse de determinar a priori y ontológicamente lo que aparece como toda la imprevisibilidad de un acto libre. No basta con catalogar las conductas, las tendencias y las inclinaciones, sino que, a demás, es preciso descifrarlas, saber interrogarlas. Esta investigación sólo se puede llevar a cabo según las reglas de un método específico, al cual Sartre denomina psicoanálisis existencial, cuyos objetivos fundamentales los podemos sintetizar en los siguientes puntos: 
1. El principio de este psicoanálisis es que el hombre es una totalidad y no una colección; que, en consecuencia, se expresa por entero en la más insignificante y superficial de sus conductas: todo es revelador en el ser humano, tics, gestos, etc.

2. El objetivo del psicoanálisis es descifrar los comportamientos empíricos del hombre, sacar a la luz las revelaciones que cada uno de ellos contiene y fijarlas conceptualmente.

3. Su punto de partida es la experiencia; su punto de apoyo, la comprensión preontológica y fundamental que el hombre tienen de la persona humana. Toda persona humana posee a priori, el sentido del valor revelador de sus manifestaciones y es capaz de descifrarlas, por lo menos si se le ayuda y se le conduce de la mano.

Como podemos deducir, el método del psicoanálisis existencial es comparativo, ya que cada conducta humana simboliza a su manera la elección fundamental que ha de sacarse a la luz, y puesto que, a la vez, cada una de ellas enmascara esa elección bajo sus características ocasionales y su oportunidad histórica, la comparación entre esas conductas nos permitirá hacer brotar la revelación única que todas ellas expresan de manera diferente. Como el primer esbozo de este método nos lo ofrece el psicoanálisis de Freud, conviene señalar con más precisión en qué aspectos del psicoanálisis existencial se inspirará en el psicoanálisis propiamente dicho, y en qué diferirá radicalmente de él.

\section{Psicoanálisis existencial y psicoanálisis empírico}

\section{Similitudes entre ambos psicoanálisis}

Ambos psicoanálisis consideran que todas las manifestaciones objetivamente observables de la "vida psíquica" mantienen relaciones de simbolización que simbolizan estructuras fundamentales y globales que constituyen propiamente la persona. Los dos consideran que no hay datos primeros: inclinaciones heredadas, carácter, etc. Por ejemplo, el psicoanálisis existencial no conoce nada antes del surgimiento originario de la libertad humana; el psicoanálisis empírico postula que la afectividad primera del individuo es una cera virgen antes de su historia, por ejemplo, la libido no es nada fuera de sus fijaciones concretas, sino una posibilidad permanente de fijarse de cualquier modo sobre cualquier objeto. Sendos psicoanálisis consideran al ser humano como una historialización permanente y procuran descubrir, más que datos estáticos y constantes, el sentido, la orientación y las vicisitudes de esa historia. Por ello, plasman al 
hombre en el mundo y no conciben que pueda interrogarse a un hombre sobre lo que es sin tener en cuenta su situación. Un ejemplo claro que utiliza mucho Freud en las investigaciones psicoanalíticas, es apuntar a reconstruir la vida del sujeto desde el nacimiento hasta el momento de la cura; utilizan todos los documentos objetivos que pueden hallar: cartas, testimonios, diarios íntimos, informaciones "sociales" de toda especie. Tanto el psicoanálisis empírico como el existencial buscan una actitud fundamental en situación que no podría expresarse por definiciones simples y lógicas, puesto que es anterior a toda lógica y que exige ser reconstruida según leyes de síntesis específicas. El psicoanálisis empírico trata de determinar el complejo, designación que de por sí indica la polivalencia de todas las significaciones implicadas; el psicoanálisis existencial trata de determinar la elección originaria. Ésta, al producirse frente al mundo y ser elección de la posición en el mundo, es totalitaria, como lo es el complejo; como el complejo, es anterior a la lógica; ella elige la actitud de la persona respecto a la lógica y los principios; no se trata, pues, de interrogarla con arreglo a la lógica. Esa elección recoge en una síntesis prelógica la totalidad del existente y, como tal, es el centro de referencia de una infinidad de significaciones polivalentes. Para estos dos psicoanálisis, el sujeto es considerado como no estando en una posición privilegiada para proceder sobre sí mismo a esas investigaciones, de ahí que se requiera la llamada conciencia del estado anómalo psíquico, es decir, reconocer que se necesita ayuda. Por ello, se presentan como un método estrictamente objetivo, que trata como documentos tanto los datos de la reflexión como los testimonios ajenos. Es claro que el sujeto puede realizar sobre sí mismo una investigación psicoanalítica, pero le será preciso renunciar de una vez a toda ventaja de su posición particular, e interrogarse exactamente como si fuera un prójimo. Y, finalmente, el objeto de ambos psicoanálisis mantiene en común tener la realidad de su ser y su conocimiento por el sujeto puede contribuir a iluminar la reflexión convirtiéndose ésta en un disfrute que será un cuasi-saber.

\section{Diferencias entre ambos psicoanálisis}

Viendo las semejanzas parecería que encontrar diferencias fuera una tarea ardua, pero el lector sabrá apreciar, por lo que lleva leído, que, en esencia ambos psicoanálisis, distan notablemente. Las similitudes se justifican, porque es claro que el psicoanálisis existencial deriva del psicoanálisis empírico y, en consecuencia poseen una base común y argumentos afines. Empero, el psicoanálisis empírico parte del postulado de la existencia de un psiquismo inconsciente que por principio se hurta a la intuición del sujeto. El psicoanálisis existencial rechaza el postulado del inconsciente: el hecho psíquico es, para él, 
coextensivo a la conciencia. Ese misterio del inconsciente proviene de una privación de los medios que ordinariamente permiten el análisis y la conceptualización. Así, los complejos extirpados de las profundidades inconscientes y los proyectos descubiertos por el psicoanálisis existencial, serán aprehendidos desde el punto de vista del prójimo. De este modo, el objeto sacado a la luz será articulado según las estructuras de la trascendencia-transcendida, es decir, que su ser será el ser-para-otro, aunque el psicoanálisis y el psicoanalizado sean la misma persona. En consecuencia, el proyecto sacado a la luz por ambos psicoanálisis será la totalidad de la persona, lo irreductible de la transcendencia, tal como son en su ser-para-el-otro. Otra importante diferencia es que el psicoanálisis empírico ha decidido por su cuenta acerca de su instancia irreductible en lugar de dejarla anunciarse por sí misma en una intuición evidente. La libido o la voluntad de poder, es claro que constituyen un residuo psicobiológico que no es claro por sí mismo y que no nos aparece como si hubiera de ser el término irreductible de la investigación. En última instancia, la experiencia establece que el fundamento de los complejos es esa libido o esa voluntad de poder, y tales resultados de la investigación empírica son enteramente contingentes y no logran convencer: nada impide concebir a priori una "realidad humana" que no se expresa por la voluntad de poder y cuya libido no constituyera el proyecto originario e indiferenciado ${ }^{14}$. Contrariamente, la elección a la que se remontará el psicoanálisis existencial precisamente por ser elección da razón de su contingencia originaria, pues la contingencia de su elección es el reverso de su libertad. Además, en cuanto se funda sobre la carencia de ser concebida como característica fundamental del ser, recibe legitimación como elección y sabemos que ya no tenemos que ir más lejos. Lo que se alberga en la conciencia como inconsciente, no es un estado mágico, todo está en nuestra conciencia, sin embargo imposibilitada de vislumbrar lo que la perturba. Eso nos lleva a ver que el psicoanálisis existencial no tiene que remontarse dese el "complejo", que es precisamente la elección de ser, hasta una abstracción, como la libido, que lo explicaría. El complejo es elección última, es elección de ser y se hace tal. El complejo es difuso y lo que necesita el analista es claridad: al ser puesto en claro, se revela cada vez como evidentemente irreductible. De ahí que ni la libido ni la voluntad de poder aparecerán al psicoanálisis existencial ni como caracteres comunes a todos los hombres ni como irreductibles. Todo lo más, puede que se compruebe, después de una investigación, que ciertos sujetos expresan, a título de conjunto particulares, una elección fundamental que no puede reducirse ni a la una ni a la otra. Es entonces

${ }^{14}$ Cfr. Ibid, pág. 592 
la elección la protagonista que fundamenta el psicoanálisis que proponemos. El psicoanálisis existencial se fundamenta en la elección, ya que renuncia a suponer una acción mecánica del medio sobre el sujeto considerado. El medio no puede obrar sobre el sujeto sino en la medida exacta en que éste lo comprende, es decir, lo transforma en situación. No vale ninguna descripción objetiva del medio ya que, desde el principio, el medio concebido como situación remite al para-sí en cuanto que elige, exactamente como el para-sí por su ser en el mundo remite al medio. Al renunciar a todas las formas de causalidad mecánicas, renunciamos a todas las interpretaciones generales del simbolismo considerado por el psicoanálisis empírico, he ahí la constatación de un ir a una realidad manifiesta. Y como nuestro objetivo no puede ser establecer leyes empíricas de sucesión, no podríamos constituir una simbología universal. El psicoanálisis deberá, cada vez, reivindicar una simbología en función de cada caso en particular. Si el ser es una totalidad, no es posible que puedan existir relaciones elementales de simbolización, que mantendrían una significación constante en cada caso, es decir, que quedaría inalterada cuando se pasa de un sistema significante a otro. Además, el psicoanálisis no perderá de vista que la elección es viviente y, por lo tanto, puede ser siempre revocada por el sujeto estudiado. Es claro que los símbolos cambian de significación porque los bruscos cambios de orientación que se dan en el individuo, obligan a éste, en ese instante, a tomar una posición nueva frente a un pasado inmutable. Ello nos obliga a abandonar la simbología utilizada hasta entonces. El psicoanálisis existencial deberá ser enteramente flexible y amoldable a los menores cambios observables en el sujeto, ya que se trata de descubrir una elección no un estado. Y, finalmente, el investigador del psicoanálisis existencial tienen como objeto descubrir una elección y, por ello, deberá tener siempre presente que su objeto no es algo hundido en las tinieblas del inconsciente, sino una determinación consciente y libre, la cual tampoco es un habitante de la consciencia, sino que se identifica con la consciencia misma. El psicoanálisis empírico, en la medida en que sus métodos valen más que sus principios, se encuentra a menudo en vías de un descubrimiento existencial, aunque siempre se detiene a medio camino, por ejemplo cuando, en su introspección, se aproxima a la elección fundamental, las resistencias del sujeto se desmontan de pronto y éste reconoce súbitamente la imagen que les es presentada como suya, igual que si se viera en un espejo. Este involuntario testimonio del sujeto es preciso para el psicoanálisis empírico, quien ve en él la señal de que ha alcanzado su objetivo: puede pasar de las investigaciones propiamente dichas a la cura. Pero nada, ni en sus principios ni en sus postulados iniciales, le permite comprender ni utilizar ese testimonio. Porque si efectivamente -tal como a firma Freud- el complejo es inconsciente, es decir, el signo está separado de lo significado por una barrera, el sujeto jamás lo 
reconocerá y, todavía más, si fuera preciso reconocerle -al paciente- la facultad de comprender los signos, eso sería hacer de él un inconsciente consciente porque comprender es tener consciencia de que ha comprendido. Así, ¿podemos decir que quien reconoce la imagen presentada es el sujeto en tanto que consciente?, pero ¿cómo compararía esa imagen con su verdadera afección, si ésta última está fuera de su alcance y nunca ha tenido conocimiento de ella? El paciente, lo más que podrá decir es que la explicación psicoanalítica de su caso es una hipótesis probable, cuya probabilidad está dada por el número de conductas que es capaz de explicar. La consecuencia es que el sujeto se encuentra, con respecto a la interpretación, en la posición de un tercero, del psicoanalista mismo, y no tiene respecto de ella posición privilegiada alguna. Y si cree en la probabilidad de la hipótesis psicoanalítica, esta simple creencia, que se dará en los límites de su conciencia, ¿podría realmente llevar consigo la ruptura de las barreras que bloquean a las tendencias inconscientes? El psicoanálisis empírico, tiene sin duda, la imagen oscura de una conciencia súbita entre lo consciente y lo inconsciente, pero se ha privado de los medios para concebir tal conciencia de modo positivo.

Por eso, nuestra propuesta de un psicoanálisis existencial, va más allá de unos mecanismos mágicos que con cierta connotación esotérica pretenden introducir estructuras en el individuo que no le corresponden. Hablar de un inconsciente significa atribuir al Yo una dimensión desconocida, deshabitada por él, resultando la dificultad de dotar de significación a esa inconsciencia que por otro lado domina al Yo de tal manera que lo lleva a su estado de incertidumbre y desubicación. Pero lo más relevante es que no se puede tener consciencia del inconsciente sino es desde una misma consciencia, así que el estado de inconsciencia depende por entro de lo consciente y eso nos lleva a revisar el concepto de inconsciencia planteándonoslo como estado o entidad propia. Si como estado puede ser un lapsus, una fallida temporalmente hablando, entonces podríamos hablar de estados inconscientes, situaciones inconscientes o actos inconscientes que quedarían justificados por su efímera temporalidad; en realidad hablaríamos de actos mecánicos o no intencionados. De otra manera, la situación de inconsciencia es insostenible ya que remite siempre a una entidad propia y recóndita del Yo. En este caso, la sostenibilidad del concepto se hace más difícil porque ¿cómo es posible que mi Yo alberge algo de lo que él -mi Yono tiene poder, no domina, no es él? Siendo el Yo un todo, una intuición directa de mí mismo, se hace imposible que exista una entidad ajena a él que lo domine. El psicoanálisis existencial explica lo que Freud llama inconsciencia como una estrategia del Yo para defenderse de las hostilidades que le muestra su ser en el mundo, es lo que Sartre denominó la Mala Fe: un autoengaño que utilizamos de forma directa para con nosotros con el objetivo de olvidar el trauma del que 
hemos sido víctimas, protagonistas u observadores. La Mala Fe no es un acto peyorativo ni para el para-sí ni para el en-sí, al contario intenta garantizar el proyecto genuino, auténtico y puro del ser-en-el-mundo. Además, no es que sea un atributo del hombre, más bien forma parte de su naturaleza de ser para que su proyecto de ser-que es el mismo vivir- no se vea alterado y si eso sucede, pueda elegir con determinación otro proyecto que lo conduzca hacia la realización del mismo. Que la mala fe forme parte de la naturaleza humana significa que los tres estadios constitutivos del ser -para-sí, en-sí y para-otro- son un bloque compacto que se plasman siendo en el mundo; esto es, la Mala Fe surge como defensa ante la presencia e intervención en mi mundo de los otros. De aquí la famosa frase, extraída fuera de contexto que da lugar, a veces, a malas interpretaciones: el infierno son los otros ${ }^{15}$. Pero también los otros son el cielo, y así evitamos el sentido pesimista con el que se tizna al existencialismo en general porque el otro es aquel que complementa mi vida, que le da sentido y que justifica mi hacer. De hecho, en la filosofía sartreana la presencia del otro tiene un papel fundamentador en el aspecto ontológico, literario, social y político ${ }^{16}$, no hay que olvidar que de las 646 páginas que tiene la obra en la edición alianza, casi 200 son dedicadas al análisis del otro.

\section{Metodología del psicoanálisis existencial}

Llegado a este punto podemos ya explicar en qué consiste la metodología del psicoanálisis existencial, la cual nos proporcionará una visión de los desequilibrios psíquicos más veraz que la del psicoanálisis empírico. Nuestro psicoanálisis nos permite sacar a la luz, con una forma rigurosamente objetiva, la elección subjetiva por la cual cada persona se hace persona, es decir, se hace anunciar a sí misma lo que es. Ya que la persona busca una elección de ser al mismo tiempo que su ser y eso le obliga a reducir los comportamientos singulares a las relaciones fundamentales de ser que se expresan en esos comportamientos. Y dado que la persona es una constante proyección en el mundo, el método existencial, se orienta desde el principio hacia una comprensión del ser y no debe asignarse otro objetivo que encontrar el ser y la manera de ser del ser frente a ese ser. No puede detenerse antes de alcanzar ese objetivo. Así, utilizará la comprensión del ser que caracteriza al investigador en tanto que él mismo es realidad humana; y, como trata de extraer el ser de sus

\footnotetext{
${ }^{15}$ Cfr. Sartre, Jean Paul, A Puerta Cerrada, Alianza Editorial, Madrid, 1989. Pág 134-135.

${ }^{16}$ Cfr. Gómez García, Juan Carlos, El ser para otro sartreano, Universidad de Barcelona, 2002. Tesis Doctoral dirigida por el doctor Agustín González.
} 
expresiones simbólicas, deberá reinventar cada vez, sobre las bases de su estudio comparativo de las conductas, una simbología destinada a descifrarlas. El criterio del éxito será el número de hechos que su hipótesis permita explicar y unificar, así como la intuición evidente de la irreductibilidad del término alcanzado. Y, los resultados alcanzados, los fines últimos del individuo podrán ser objetos de una clasificación y ser comparados con otros resultados estableciendo consideraciones generales sobre la realidad humana en cuanto elección empírica de sus propios fines. Finalmente, las conductas estudiadas por este psicoanálisis existencial, no serán solamente los sueños, actos fallidos, las obsesiones y la neurosis, sino también y, sobre todo, los pensamientos de la vigilia, los actos logrados y adaptados, el estilo, etc. Porque la voluntad del paciente ante la determinación de la cura, es fundamental para localizar el mal psíquico.

\section{Conclusión: psicoanálisis existencial y práctica filosófica.}

El psicoanálisis existencial es una propuesta fundamentadora, terapéutica y conductora que la práctica filosófica puede desarrollar en el asesoramiento filosófico. Fundamentadora, ya que es la única propuesta psicoanalítica que basa su desarrollo terapéutico en un análisis ontológico previo, terapéutica porque muestra una forma de reconducción analítica donde el sujeto es dominante de sus desequilibrios psíquicos y conductora en el sentido más amplio del término, porque el individuo conduce sus decisiones en un mundo pleno de incertidumbre; se trata, no tanto de prevenirle sino más de canalizarle hacia una analítica introspectiva basada en la observación genérica de sus haceres.

Desde el existencialismo, consideramos al hombre en situación, eso significa muchas cosas; primero que el sujeto solo, no es nada, necesita de una sociedad para desarrollar su ser; segundo, que ese desarrollo se da en un conflicto de origen, en una dialéctica de la cosificación perpetua e insoslayable, ya que todo ser está sujeto a su libertad, está condenado a ser libre y a guiar dicha libertad por el mundo y tercero, al sujeto le faltan pautas conductoras para afrontar esa contradicción que significa mantener inalterable su Yo en defensa de la agresión exterior. Esto es, el mero hecho de ser, de tener conciencia de analítica de la vida, implica un ser existenciario que se encuentra en un mundo que no comprende y del que se siente una pura víctima. El psicoanálisis existencial ayuda a comprendernos, comprender a los otros y comprender el sentido de la absurdidad de la vida; comprender que lo absurdo es lógico de por sí, que vivimos en una absurdidad a la que le damos la espalda y cuando nos giramos, no la reconocemos como tal. Hemos de aprender a vivir en ella, de ella y con ella porque ella forma parte de nuestra existencia. $Y_{\text {¿cómo es posible una }}$ 
terapia de esa índole? ¿Funciona como prevención o como seguimiento al conflicto psíquico ya iniciado?

El ser humano se proyecta constantemente, por ello decimos que es libre, o mejor, que es libertad queriendo significar que libertad y hombre es lo mismo. Así, no tiene más remedio que proyectarse en su elección continua; dichos proyectos son lo que el hombre es o acaba siendo, empero no es siempre así, el hombre, en realidad, es nada de ser porque siempre, sus proyectos, son comunes, nunca genuinos y son propios en la medida en que son actos individuales, pero su valúa se disipa en actos comunes, vulgares que lo que hacen es desvirtuar la individualidad del ser, siendo eso, nada de ser. Jamás realizamos un acto que nos excluya de lo propio del ser humano (por ello el hombre quiere ser Dios), si nos preguntan qué somos, qué es lo que te hace ser tú y no otro, siempre contestaremos como podría contestar cualquiera, y es esa vulgaridad la que nos aproxima a la nada de ser, la cual, nunca atrapamos porque siempre somos estando en relación contingente. Jamás atrapamos a nuestro yo en su autenticidad porque siempre somos algo, y nunca somos nada que es lo que realmente somos, el ser que es lo que no es y que no es lo que es. Pero esta nada de ser está lejos de nuestro proyecto que siempre es en situación, en acto puro (sin potencialidades); el hombre se comprende como una hacedor que vive constantemente el desarraigo con su proyecto cuando éste no es llevado a su fin. Elijo hacer esto o lo otro y en la elección va mi vida, mi ser, mi existenciario. La victoria de la elección, el éxito significa mi cumplimiento, mi persona, mi yo ganador delante de los otros; me he forjado un ser, una seudonaturaleza; sin embargo, el incumplimiento del proyecto es el fracaso, la desolación, el surgimiento de reflexiones profundas sobre mi valía como ser social, la victoria del otro, el ser un objeto y, lo más grave, si no proyecto inmediatamente otro proyecto sustitutorio que compense el anterior, caeré en la depresión, en la asunción de mi nihilidad y la proximidad con la nada de ser, que significaría el descontrol de mi mismo. Algunos lo denominan inconsciencia, nosotros mala Fe, huida del ser de una realidad que no supera, identificación con el absurdo, esto es, creer que la salida es la no elección. Es lo que los psicólogos denominan depresión. Nosotros lo denominamos huída fallida porque el individuo elije la posibilidad de no elegir significando que no es un ser libre; en consecuencia entra en contradicción ya que elije el no elegir. Muestra entonces una actitud de desolación e incertidumbre, inseguridad y vacío de ser porque sus proyectos han sido un fracaso y como la vida es un proyecto, él mismo se siento fracasado en la vida.

El psicoanálisis existencial propone un análisis exhaustivo de esa situación, personalizándola y argumentándola, con la finalidad de que el individuo se vea, 
elija verse, se auto valúe y se juzgue en situación concreta, jamás abstracta, simbólica o interpretativa.

Creemos que debemos impulsar la práctica filosófica desde todos los ámbitos que podamos, centros cívicos, talleres, cafés filosóficos, etc. Hoy más que nunca, el ciudadano de a pie precisa de orientaciones basadas en la seguridad que nos da la razón, la argumentación y el análisis; alejarnos de las supersticiones y los dogmas para aproximarnos a un análisis sincero, meticuloso y serio; éste es el propósito del existencialismo que no sólo desarrolla su actividad como terapia conductora, sino que también lo hace como prevención. Pensamos que el análisis ontológico aquí planteado, expresado en una terminología, quizás más asequible para el público ajeno a la filosofía, sirve para ubicarnos en eso que somos, para vernos desde una perspectiva analítica descriptiva y poder comprendernos, poder examinarnos a nosotros mismos, a los otros y a nuestras relaciones con los otros, causa, sin duda, de los avatares del ser. De este modo podemos prevenir conflictos o bien hacerles frente con la seguridad que da el acercamiento a una comprensión del ser. Sin embargo nos encontramos con serias dificultades a la hora de hacer extensivo nuestro proyecto, la primera es el carácter elitista del lenguaje filosófico, que aleja a los curiosos y aburre a los estudiantes de bachillerato; los primero suelen optar por recursos de carácter más vulgar y flexible, en todos los sentidos, a saber, la autoayuda. No ven en la filosofía una práctica real que pueda llegar a ser de su dominio, lo esotérico, lo religioso y los gabinetes psicológicos, parecen ser el recurso más común y factible para llevar a cabo esa reconducción, esa ayuda que se necesita para orientarte y conducirte en el vivir. Por ello, hemos de potenciar la práctica filosófica a todos los niveles que podamos, acercarnos como malabaristas haciendo piruetas para atraer al vulgo a la razón. Este discurso parecería estar impregnado de un cierto dogmatismo y asemejarse a la defensa de una metodología abanderada por la verdad absoluta, lejos de eso, la única bandera que ondeamos es la de la defensa a la libertad de pensamiento, al derecho a ser autosuficiente, a aprender a utilizar los juicios de razón; todo ello para tener argumentos sólidos que puedan hacer del vivir una existencia auténtica.

Seguramente, el término psicoanálisis existencial es desconocido para muchos, incluso en el ámbito filosófico, ya que el psicoanálisis es una metodología propia de Freud y modificada por otros a lo largo de los últimos años. Podríamos decir que el psicoanálisis existencial es una vertiente más del psicoanálisis denominado empírico que representaba su creador, es una revisión de los conceptos fundamentales modificados desde una perspectiva exclusivamente existencial porque creemos que sólo desde la existencia podemos dar garantía de una metodología que se aproxime más a la descripción del ser y a 
su realidad empírica. Si tuviéramos que señalar esa diferencia como hilo conductor, diríamos que es, fundamentalmente, el concepto de consciencia e inconsciencia. Creemos, desde el psicoanálisis existencial que la consciencia no alberga ningún Yo ni más estructuras afines. El Yo no es un habitante de la consciencia, es ella misma habitando en el mundo. Esto significa que toda terapia psicoanalítica se enfrenta a una realidad desnuda, despojada de todo artificio o tecnicismo que no guíen por caminos irreales, simbólicos y recónditos; eso es caer en una situación irracional donde el dominio de la razón se halla en la sin razón, en la irracionalidad; es decir, en el inconsciente. Afirmarlo significa darle forma a un ser que no es por principio lógico, lo inconsciente no tiene una voluntad conductiva sobre el Yo porque no existe. Ser inconsciente, eso que denominan los psicoanalistas empíricos como la barrera de la razón, es únicamente una estructura del Yo que en su dimensión cobra una característica de involuntariedad o voluntariedad negativa. $\mathrm{Si}$ realizamos un análisis psicoanalítico desde la admisión de una estructura vacía de contenido, tanto lógico como real, nuestro análisis se diluye en la irracionalidad y la fantasía. Lejos de eso, el psicoanálisis existencial pretende dar forma a la realidad humana desde esa descripción óntica, que decíamos, del ser. El ser es su manifestación en el mundo, sus múltiples relaciones sociales y su satisfacción, o insatisfacción, constante del cumplimiento de sus proyectos como tales. Y ese ser que vive, existe y muere ansía comprender qué le pasa en qué situaciones; ansía saber qué determinación seguir en qué momentos. Necesita aprender a utilizar la razón y eso sólo puede ser labor del filósofo, tal como señaló en muchas ocasiones Sócrates.

\section{Bibliografía}

BINSWANGER, LUDWING, Obras escogidas, RBA Biblioteca del psicoanálisis 2006.

DESCOMBES, VINCENT, Lo mismo y lo otro, Cátedra, Madrid, 1982.

FREUD, SIGMUND, El malestar en la cultura, Alianza Editorial, Madrid, 2006 GÓMEZ GARCÍA, JUAN CARLOS, El ser para otro sartreano, Universidad de Barcelona, Barcelona. 2002. Tesis doctoral.

HEIDEGGER, MARTIN, El ser y el tiempo, Fondo de Cultura Económica, Madrid 1989.

ONFRAY, MICHEL, Freud: El crepúsculo de un ídolo, Taurus, Madrid, 2011. SARTRE, JEAN PAUL, El ser y la nada, Alianza Universidad, Madrid 1989. 
SARTRE, JEAN PAUL, A puerta cerrada, Alianza Losada, Madrid, 1989.

WEBSTER, RICHARD, Por qué Freud estaba equivocado, Destino, Barcelona, 2002. 